\title{
A PROTEÇÃo AO MEIO AMBIENTE E A VEDAÇÃo À CRUELDADE CONTRA OS ANIMAIS: ANÁLISE JURÍDICA DO CONSUUMO DE QUELÔNIOS POR COMUNIDADES LOCAIS NA AMAZÔNIA
}

\begin{abstract}
ENVIRONMENT PROTECTION AND ANIMAL CRUELTY PROHIBITION: LEGAL ANALYSIS OF TURTLES CONSUMPTION BY AMAZON LOCAL COMMUNITIES
\end{abstract}

\author{
Victória Braga Brasil' \\ Túlio Macedo Rosa e Silva ${ }^{23}$
}

\section{RESUMO}

É prática comum o consume de quelônios na Região Amazônica, com o hábito difundido através das comunidades locais, que enxergam na Tartaruga da Amazônia e "tracajás" verdadeiras iguarias, de alto valor e prestígio culinário. Há, ainda, o hábito de se extrair os ovos, seja, a prole dos quelônios, a fim de que esses também sejam consumidos ou sirvam de base para cosméticos. Trata-se de pressão que leva à diminuição da população das espécies envolvidas na Região, com grande chance de extinção. Da mesma maneira como o ordenamento jurídico pátrio se propôs a proteger aspectos culturais, também o fez em relação ao Meio Ambiente, com o dever e direito de preservação desse para as presentes e futuras gerações, o que inclui a fauna e a flora. Há, ainda, extraído da própria Constituição da República Federativa do Brasil de 1988, a vedação à crueldade contra animais, prática que se encontra na forma como se mata a tartaruga. Diante da preocupação com a extinção da espécie e a crueldade envolvida no processo, o presente trabalho se propõe a estudar quais direitos devem prevalecer em tais circunstâncias. Para o cumprimento do objetivo proposto, o artigo, de caráter monográfico, possui o método dedutivo, de conclusões genéricas a específicas, com ampla revisão da bibliografia disponível, formada por livros, papers e legislação.

\footnotetext{
${ }^{1}$ Mestranda em Direito Ambiental pelo Programa em Direito Ambiental do Programa de Pós-graduação em Direito Ambiental do=a Universidade do Estado do Amazonas (PPGDA - UEA). Bacharel em Direito pela Universidade do Estado do Amazonas (ESO/UEA). E-mail: victoriabbrasil@live.com. ORCID: https://orcid.org/0000-0001-7426-1500

2 Doutor em Direito e Processo do Trabalho pela Universidade de São Paulo (USP). Mestre em Direito e Processo do Trabalho pela Universidade de São Paulo. Professor do Mestrado em Direito Ambiental pelo Programa de Pós-graduação em Direito Ambiental da Universidade do Estado do Amazonas (PPGDA UEA). E-mail: tuliomasi@hotmail.com. ORCID: https://orcid.org/0000-0001-5004-2637

${ }^{3}$ Programa de Pós-graduação em Direito Ambiental da Universidade do Estado do Amazonas (PPGDA UEA).
} 
Palavras-chave: Consumo de quelônios; Ameaça de extinção; Meio Ambiente ecologicamente equilibrado; vedação à crueldade.

\begin{abstract}
Itis a common practice the consumption of turtles in the Amazon Region, and the practice is widespread through local communities, who see in the Amazon Turtle and "tracajás" true delicacies of high value and culinary prestige. There is also the habit of extracting the eggs, that is, the offspring of the turtles, so that they are also consumed or serve as a basis for cosmetics. This is presume that leads to a decrease in the population of species involved in the Region, with a high chance of extinction. Just as the homeland legal system set out to protect cultural aspects, it did so in relation to the environment, with its duty and right to preserve it for present and future generations, including fauna and flora. There is also extracted from the Constitution of the Federative Republic of Brazil of 1988, the prohibition of cruelty to animals, a practice that is found in the way the turtle is killed. Given the concern with the extinction of the species and the cruelty involved in the process, the present work proposes to study which rights should prevail in such circumstances. To fulfill the proposed objective, the article, of a monographic character, has the deductive method, from generic to specific conclusions, with a wide review of the available bibliography, consisting of books, papers and legislation.
\end{abstract}

Key words: Turtles consumption; Extinction threat; Ecologically balanced environment.

\title{
1 INTRODUÇÃO
}

Da lição de Borges, Rezende e Pereira (2009, p. 448), extrai-se que a ação do homem sobre o meio ambiente acompanha o próprio desenvolvimento da história humana. É dos autores que se retira que "desde muito tempo vem-se utilizando os recursos naturais como fonte de vida, ou seja, para a sua própria necessidade de subsistência". Trata-se, aliás, de uma consequência da evolução humana, à medida em que o homem adquire técnica suficiente para a dominação dos recursos naturais, das ferramentas e dos animais para alimentação.

Diegues e Arruda (2001, p. 129) demonstram que desde o início da civilização povos e comunidades locais até reconheceram a existência de sítios geográficos, detentores de características especiais. A essas se concedia proteção por conta de serem fontes de caça, plantas medicinais, de água, madeira e demais recursos naturais. Há, porém, uma mudança de cenário com o crescimento demográfico, quando 
também se aumenta a capacidade produtiva humana e se gera uma maior pressão ambiental (BORGES; REZENDE; PEREIRA, 2009, p. 450).

Ou seja, a destruição e o consumo em demasiado podem levar à extinção de espécies da fauna e da flora, em um ato de inestimável prejuízo para a biodiversidade existente no planeta. No caso da Região Amazônica, o grupo dos quelônios, composto pelas espécies da Tartaruga da Amazônia, "tracajás", "jabuti" e "iaçá", encontra-se ameaçado de extinção, pois há muito é objeto de consumo local desenfreado, potencializado pela captura dos ovos também para a alimentação (SMITH, 1979, p. 88).

Do trabalho de Smith (1979, p. 87), extrai-se que se trata de uma prática longínqua, remetendo-se até mesmo ao período colonial. $O$ autor, há pelo menos quatro décadas, já deixou registrado a leniência com que se age em relação à prática ilegal de caça e consumo desse animal silvestre, atualmente ameaçado de extinção (MOREIRA; SILVA; BALESTRA, 2016, p. 3).

A complacência deriva da concepção de que se trata de um hábito cultural, com importância histórica e que constitui verdadeira manifestação da tradição de um povo, Por outro lado, o legislador pátrio, após grande e longo esforço dos agentes sociais, fez a opção de constitucionalizar a proteção ambiental, concedendo proteção com o status de direito fundamental, em benefício das futuras e presentes gerações (BRASIL, 1988, art. 225).

Houve, ainda, a aprovação da lei de Crimes Ambientais, dez anos após a promulgação da Constituição, em clara tentativa de se tentar consolidar a proteção ambiental, oportunidade em que se transformaram em crimes diversas práticas até então tratadas apenas como contravenções (FREITAS; FREITAS, 2006, p. 24).

De igual maneira, a melhor leitura do artigo 225 da Constituição aponta para a existência de um direito autônomo dos animais, relacionado à vedação de práticas cruéis e maus-tratos contra as espécies (ATAÍDE JÚNIOR, 2018, p. 56). E a crueldade se faz presente no abate artesanal dos quelônios, à medida em que as tartarugas são mortas após serem estranguladas, terem o seu pescoço quebrado e cortado diversas vezes, para que se extraía o sangue do animal, utilizado até mesmo em receitas.

Diante do conflito entre uma prática local, considerada cultural, e as normas que protegem o Meio Ambiente e os animais, questiona-se: deve o hábito de consumo de 
quelônios ser considerado como uma manifestação cultural e, portanto, lícita, tendo em vista a frequência e historicidade em que ocorre para a população amazônica?

O presente artigo buscará responder a esse questionamento a partir de ampla revisão jurídica, enfrentando-se, inclusive, a possibilidade de regulamentação como prática cultural, de acordo com a redação do recém-incluso parágrafo 7º, do artigo 225 da Constituição, analisando-se ainda como deve um magistrado ponderar sobre tais direitos em conflito em um caso concreto.

\section{A IMPOSSIBILIDADE DE CARACTERIZAÇÃO DO CONSUMO DE TARTARUGA COMO MANIFESTAÇÃO CULTURAL E O DIREITO AO MEIO AMBIENTE EQUILIBRADO}

Como se extrai do trabalho de Rebêlo e Pezzuti (2000, p. 85), "tartarugas e outros quelônios têm sido caçados, pescados e seus ovos colhidos há muitas gerações na Amazônia". E isso decorre do fato de que sua carne, e mesmo os seus ovos, serem considerados iguarias muito apreciadas pela comunidade local, sendo culturalmente importantes para muitos municípios da Região Amazônica. Os pesquisadores (2000, p. 86), ao compilar diversos estudos, concluem e demonstram como se trata de um processo histórico:

A longa história de uso da tartaruga permite identificar pelo menos quatro fases. Na primeira fase (1700-1860), estima-se que foram colhidos 12-48 milhões de ovos por ano para a produção de óleo. $\mathrm{Na}$ segunda fase (1870-1897), a produção caiu para 1-5 milhões de ovos por ano. Na terceira fase, a partir do começo do século, a produção caiu ainda mais, para menos de 300 mil ovos por ano (SMITH, 1974). Na quarta fase, a série relatada (1976-1988) da produção das praias protegidas registrou entre 18 mil e 1,6 milhão de filhotes, numa série mais ou menos crescente (IBAMA 1989). Revela-se ainda que há populações viáveis de tartaruga, mas a produção média é comparável à produção do começo do século XX.

Os antigos habitantes da Amazônia já colhiam ovos em grandes festivais e faziam pescarias coletivas antes da chegada dos europeus à região, mas foi após o início da colonização que o comércio de ovos e adultos se intensificou; óleo, banha e carne tornaram-se produtos, mercadorias de valor, fontes de renda e outros benefícios concretos e ilusórios. Este padrão de uso, segundo critérios predominantemente mercantis, levou a uma redução drástica e declínio constante das populações ao longo dos últimos séculos, e diagnósticos recentes indicaram que, mesmo com imposição de regras e organização, a captura destes animais e a coleta de seus ovos, foram predatórias, sistemáticas e ocorreram em toda sua 
área de distribuição (FERRARINI, 1980; FAO/PNUMA, 1985; GILMORE, 1986; LUXMOORE et al 1988; IBAMA, 1989).

Trata-se, aliás, de situação bastante delicada, que contrapõe os interesses de uma comunidade local, consumidora do que considera uma iguaria, em face a espécies ameaçadas de extinção, entre as quais se incluem o maior quelônio de água doce da América do Sul, a Tartaruga da Amazônia (IBAMA, 1989). Como se extrai do trabalho de Rebêlo e Pezzuti (2000, p. 87), há muito se transformou a caça ilegal em um "caso de polícia”, pelo menos desde o período compreendido como Regime Militar (1976).

Recentemente, porém, o Congresso Nacional aprovou a Proposta de Emenda Constitucional 096/2017, a qual foi constituída como uma reação ao julgamento da Ação Direta de Inconstitucionalidade n 4.983, que julgou inconstitucional a Lei Estadual n 15.299/2013, do Estado do Ceará. Mesmo que a Emenda trate de prática desportiva que utilize animais, vê-se uma clara tentativa de flexibilizar a proteção concedida aos animais (vedação à crueldade e aos maus-tratos) em favor de manifestações que se considerem culturais. Deu-se a seguinte redação:

As Mesas da Câmara dos Deputados e do Senado Federal, nos termos do $\S 3^{\circ}$ do art. 60 da Constituição Federal, promulgam a seguinte Emenda ao texto constitucional ${ }^{4}$ :

Art. $1^{\circ} \mathrm{O}$ art. 225 da Constituição Federal passa a vigorar acrescido do seguinte $\S 7^{\circ}$ :

"Art. 225.

$\S 7^{\circ}$ Para fins do disposto na parte final do inciso VII do $\S 1^{\circ}$ deste artigo, não se consideram cruéis as práticas desportivas que utilizem animais, desde que sejam manifestações culturais, conforme o $\S 1^{\circ}$ do art. 215 desta Constituição Federal, registradas como bem de natureza imaterial integrante do patrimônio cultural brasileiro, devendo ser regulamentadas por lei específica que assegure 0 bem-estar dos animais envolvidos."(NR)

Art. 2ำ Esta Emenda Constitucional entra em vigor na data de sua publicação.

Trata-se de argumento que não deve prosperar, pois a Constituição da República Federativa do Brasil de 1988 buscou dar um tratamento especial ao Meio Ambiente. José Afonso da Silva (2014, p. 825) afirma que "o capítulo do meio ambiente é um dos mais importantes e avançados da Constituição de 1988". Vladimir Passos de Freitas

$4 \quad$ Ver em: http://www.planalto.gov.br/ccivil_03/constituicao/emendas/emc/emc96.htm. 
(2001, p. 31) anota que "dedicando ad tema, antes não tratado a nível constitucional, todo um capítulo, bem como pelo fato de ter inovado na forma de repartição de poderes".

A principal técnica de tutela do Meio Ambiente na Constituição da República de 1988 está contida em seu artigo 225, pois "cuida-se de dispositivo que, pela sua complexidade e feição original, certamente merece estudo muito mais aprofundado" (BENJAMIN ,2008, p. 54). Para Milaré $(20014,213)$ é um "direito público subjetivo, vale dizer, exigível e exercível em face do próprio Estado, que tem, também, a missão de protegê-lo". É a redação do artigo:

CONSTITUIÇÃO DA REPÚBLICA FEDERATIVA DO BRASIL DE 1988

TÍTULO VIII

DA ORDEM SOCIAL

CAPÍTULO VI

DO MEIO AMBIENTE

Art. 225. Todos têm direito ao meio ambiente ecologicamente equilibrado, bem de uso comum do povo e essencial à sadia qualidade de vida, impondo-se ao poder público e à coletividade o dever de defendê-lo e preservá-lo para as presentes e futuras gerações.

$\S 1^{\circ}$ Para assegurar a efetividade desse direito, incumbe ao poder público:

I - preservar e restaurar os processos ecológicos essenciais e prover o manejo ecológico das espécies e ecossistemas;

II - preservar a diversidade e a integridade do patrimônio genético do País e fiscalizar as entidades dedicadas à pesquisa e manipulação de material genético;

III - definir, em todas as unidades da Federação, espaços territoriais e seus componentes a serem especialmente protegidos, sendo a alteração e a supressão permitidas somente através de lei, vedada qualquer utilização que comprometa a integridade dos atributos que justifiquem sua proteção;

IV - exigir, na forma da lei, para instalação de obra ou atividade potencialmente causadora de significativa degradação do meio ambiente, estudo prévio de impacto ambiental, a que se dará publicidade;

V - controlar a produção, a comercialização e o emprego de técnicas, métodos e substâncias que comportem risco para a vida, a qualidade de vida e o meio ambiente;

$\mathrm{VI}$ - promover a educação ambiental em todos os níveis de ensino e a conscientização pública para a preservação do meio ambiente;

VII - proteger a fauna e a flora, vedadas, na forma da lei, as práticas que coloquem em risco sua função ecológica, provoquem a extinção de espécies ou submetam os animais a crueldade.

(...) 
Na lição de Derani (1998, p. 92), o Meio Ambiente ecologicamente equilibrado funda-se como o resultado de diversos fatores sociais, os quais permitem e impõem a sua cristalização sob forma jurídica, dando-se relevância para o desenvolvimento das relações sociais. Não se afigura lícito, portanto, que o meio ambiente seja tratado de forma desprezível, menor, acessório ou mesmo subsidiário (RAPOSO, 1994, p. 115).

Está-se diante de um momento em que as interações do homem devem levar em consideração problemas sociais e ecológicos (AYALA, 2010, p. 11), tanto que a Constituição, na condição de norma-matriz, estabelece um direito fundamental ao meio ambiente ecologicamente equilibrado, ao passo que também constitui o dever, positivo, de cuidar desse ambiente, com obrigações de fazer determinadas ao Poder Público (AYALA, 2011, p. 42).Benjamin (2008, p. 41-42) assim comenta sobre a importância do meio ambiente para as relações sociais:

Uma Constituição que, na ordem social (o território da proteção ambiental), tem como objetivo 'assegurar o bem-estar e a justiça sociais' (art. 193 - grifamos) não poderia, mesmo, deixar de acolher a proteção do meio ambiente, reconhecendo-o como bem jurídico autônomo e recepcionando-o na forma de sistema, e não como um conjunto fragmentário de elementos - sistema que, já apontamos, organiza-se como ordem pública constitucionalizada.

$\mathrm{Na}$ adoção desta concepção holística e juridicamente autônoma, o constituinte de 1988, ao se distanciar de modelos anteriores, praticamente fez meia-volta, admitindo que (a) o meio ambiente apresenta os atributos requeridos para seu reconhecimento jurídico expresso no patamar constitucional, (b) proteção, esta, que passa, tecnicamente, de tricotômica a dicotômica (pois no novo discurso constitucional vamos encontrar apenas dispositivos do tipo iuscogens e iusinterpretativum, mas nunca iusdispositivum) - o que banha de imperatividade as normas constitucionais e a ordem pública ambiental; além disso, trata-se de (c) salvaguarda orgânica dos elementos a partir do todo (a biosfera) e (d) do todo e seus elementos no plano relacional ou sistêmico, e já não mais na perspectiva da sua realidade material individualizada (ar, água, solo, florestas, etc), (e) com fundamentos éticos explícitos e implícitos, entre aqueles a solidariedade intergeracional, vazada na preocupação com as gerações futuras e, entre estes, com a atribuição de valor intrínseco à Natureza, (f) tutela viabilizada por instrumental próprio de implementação, igualmente constitucionalizado, como a ação civil pública, a ação popular, sanções administrativas e penais e a responsabilidade civil pelo dano ambiental o que não deixa os direitos e obrigações abstratamente assegurados ao sabor do acaso e da má vontade do legislador ordinário. 
Seguindo a orientação constitucional, o Congresso Brasileiro aprovou a Lei 9.605 de 12 de fevereiro de 1998, marco final do aparato legislativo para zelar pela proteção ao direito ambiental (FREITAS; FREITAS, 2006, p. 24). Como se vê do texto legal, não há uma definição expressa do que seja crime ambiental. Recorre-se, portanto, à lição de Damásio de Jesus (2005, p. 153);

Para que haja crime é preciso, em primeiro lugar, uma conduta humana positiva ou negativa (ação ou omissão). Mas nem todo o comportamento do homem constitui delito. Em face do princípio da reserva legal, somente os descritos pela lei penal podem assim ser considerados.

(...)

Fato humano tipicamente previsto por norma jurídica sancionada mediante pena em sentido estrito (pena criminal), lesivo ou perigoso para bens ou interesses considerados merecedores da mais enérgica tutela.

Como ensina Costa Neto (2003, p. 316), a Lei oㅡ 9.605 de 1998 dedicou espaços específicos para tratar de crimes contra a fauna, a flora, contra a poluição, o ordenamento urbano e o patrimônio cultural e, além, contra a administração ambiental. Para Takada e Ruschel (2012, p. 1050), o "progresso por ela ensejado foi mais político do que técnico-jurídico, continuando os juristas pátrios com o débito de escrever para nossa sociedade um direito ambiental penal à altura". Takada e Ruschel (2012, p. 10501051) anotam o seguinte sobre as penas:

Ao se referir às sanções penais, a Lei 9.605, de 12.02.1998, no que concerne às sanções penais, procurou adaptar-se às diretrizes que vem sendo traçadas pela política criminal e ambiental de nosso País. Tratase de alcançar formas alternativas de impor sanção ao condenado, mas evitando, dentro do possível, seu encarceramento e o contato com outros presos. No âmbito específico do Direito Ambiental há o princípio da prevenção, uma das vigas mestras do Direito Ambiental. O legislador levou em consideração tal circunstância, procurando, além do caráter de retribuição e de castigo das penas, dar ênfase ao seu caráter preventivo. Nos dias atuais, a tutela penal do meio ambiente continua sendo uma necessidade indispensável, especialmente quando as medidas nas esferas administrativa e civil não surtirem efeitos desejados. A medida penal tem por escopo prevenir e reprimir condutas praticadas contra a natureza.

$\mathrm{Na}$ verdade, a garantia do meio ambiente saudável transcende o que está nas leis, parecendo próxima do direito natural do ser humano. Atenta a isso, nossa Lei Maior, em seu art. 225, $\S 3^{\circ}$, estabeleceu que "as condutas e atividades consideradas lesivas ao meio ambiente 
sujeitarão os infratores, pessoas físicas ou jurídicas, a sanções penais e, administrativas, independentemente da obrigação de reparar os danos causados".

Como se extrai da obra de Vladimir Passos de Freitas e Gilberto Passos de Freitas (2005, p. 292), há tipos penais que levam, inclusive, à restrição de liberdade, por reclusão e detenção, sendo esses os crimes mais graves previstos na lei. Para Takada e Ruschel (2012, p. 1052), tem-se, na grande maioria, que a punição por esses crimes não ultrapassará os quatro anos de pena. Deve ser destacado que, por serem os quelônios animais silvestres e em risco de extinção, a sua caça e consumo constituem verdadeiro ilícito. Eis o artigo:

CAPÍTULO V

DOS CRIMES CONTRA O MEIO AMBIENTE SEÇÃO I

DOS CRIMES CONTRA A FAUNA

Art. 29. Matar, perseguir, caçar, apanhar, utilizar espécimes da fauna silvestre, nativos ou em rota migratória, sem a devida permissão, licença ou autorização da autoridade competente, ou em desacordo com a obtida:

Pena - detenção de seis meses a um ano, e multa.

$\S 1^{\circ}$ Incorre nas mesmas penas:

I - quem impede a procriação da fauna, sem licença, autorização ou em desacordo com a obtida;

II - quem modifica, danifica ou destrói ninho, abrigo ou criadouro natural; III - quem vende, expõe à venda, exporta ou adquire, guarda, tem em cativeiro ou depósito, utiliza ou transporta ovos, larvas ou espécimes da fauna silvestre, nativa ou em rota migratória, bem como produtos e objetos dela oriundos, provenientes de criadouros não autorizados ou sem a devida permissão, licença ou autorização da autoridade competente.

$\S 2^{0}$ No caso de guarda doméstica de espécie silvestre não considerada ameaçada de extinção, pode o juiz, considerando as circunstâncias, deixar de aplicar a pena.

$\S 3^{\circ}$ São espécimes da fauna silvestre todos aqueles pertencentes às espécies nativas, migratórias e quaisquer outras, aquáticas ou terrestres, que tenham todo ou parte de seu ciclo de vida ocorrendo dentro dos limites do território brasileiro, ou águas jurisdicionais brasileiras.

$\S 4^{\circ}$ A pena é aumentada de metade, se o crime é praticado:

I - contra espécie rara ou considerada ameaçada de extinção, ainda que somente no local da infração;

(...) 
Evidente, portanto, que o consumo de tartaruga não pode de forma alguma ser considerado como manifestação cultural. Não devendo ser tolerado, incentivado ou mesmo ser reprimido de forma leniente e complacente sob a justificativa de se tratar de hábito de comunidades locais. Com as espécies ameaçadas de extinção, há verdadeira violação à Constituição da República Federativa do Brasil com a prática, dada a ameaça à fauna e à biodiversidade.

\section{A CRUELDADE INERENTE NA PRÁTICA DO CONSUMO DE TARTARUGA - VIOLAÇÃO AOS DIREITOS DOS ANIMAIS}

Além de constituir verdadeira violação aos direitos e deveres de preservação da fauna e da biodiversidade, constitucionalmente previstos, impõe-se também a análise da crueldade inerentemente praticada contra os animais no consumo de quelônios na Região Amazônica.

Como mencionado, inclusive para a elaboração de um dos pratos mais típicos", o sarapatel,a tartaruga é morta com o seu pescoço sendo estrangulado e torcido, efetivamente quebrado, para que após Ihe seja desferido vários golpes, que permitirão o escorrimento do sangue para ser armazenado e utilizado em receitas. $E$ a crueldade também é vedada em nosso ordenamento jurídico (ATAÍDE JÚNIOR, 2018, p. 52).

Antes mesmo da promulgação da Constituição da República Federativa do Brasil de 1988, compreendida como o marco legal que institui o Direito Animal autônomo no Brasil, pode se constatar a existência de leis esparsas sobre o tema, muitas das quais foram recepcionadas pelo texto constitucional (ATAIDE JÚNIOR, 2018, p. 5). Conforme a lição de Leval (2004, p. 30), o Decreto 16.590/1924 é a primeira legislação a assegurar algum direito aos animais, dada a previsão em seu artigo $5^{\circ}$ da proibição de licença para "corridas de touros, garraios, novilhos, brigas de galo e canários e quaisquer outras diversões desse gênero que causem sofrimento aos animais".

Ataide Júnior, contrapondo-se ao pensamento de Leval, identifica como primeira lei do Direito Animal brasileiro o Decreto 24.645/1934, o qual "na sua vigência original, constituiu-se no verdadeiro estatuto jurídico geral dos animais" (2018, p. 55). Pelo referido Decreto, estabeleceu-se a tutela pelo Estado de todos os animais do país, 
identificados pelo artigo 17 como sendo "todo ser irracional, quadrúpede ou bípede, doméstico ou selvagem, exceto os daninhos" (BRASIL, 1934).

A principal mudança trazida pelo Decreto foi a "tutela jurisdicional dos animais" (ATAIDE JÚNIOR, 2018, p. 56), pois o artigo 2ํㅡ, caput, trouxe a previsão expressa de que todo animal, potencial ou efetivamente vítima de maus-tratos, goza do direito de estar em juízo, assistido pelo Ministério Público, seus substitutos legais ou membros da sociedade, protetores de animais (GORDILHO; SILVA, 2012, p. 333). Sobre a importância do tema, Ataide Júnior (2018, p. 57) comenta o seguinte:

Mesmo que a legislação civil brasileira não confira, expressamente, personalidade civil aos animais, ou status jurídico de pessoas, a capacidade de ser parte a eles atribuída pelo Decreto 24.645/1934 já Ihes posicionou, dentro do direito positivo, como sujeitos de direitos passíveis de tutela jurisdicional. Sabe-se que a personalidade judiciária não depende da personalidade civil. Entes despersonalizados têm direitos e podem defender esses direitos em juízo, por meio de seus representantes legais. Os animais, muito embora ainda não contem com personalidade civil positivada, são titulares do direito fundamental à existência digna, derivado da regra constitucional da proibição da crueldade, e podem ir a juízo, como dito anteriormente, por meio do Ministério Público, de seus substitutos legais ou das associações de defesa animal, conforme regra, positiva e vigente, do art. $2^{\circ}$, parágrafo 3ำ, do Decreto 24.645/1934.

O Decreto-Lei no 3.688/1941, a Lei de Contravenções Penais (BRASIL, 1941) e, a posteriori, a Lei dos Crimes Ambientais (BRASIL, 1998) alteraram a repressão penal à crueldade trazida pelo Decreto de 1934. Mantém-se, porém, a sua importância para o exercício interpretativo para os tipos penais mais abertos e genéricos (ATAIDE JÚNIOR, 2019, p. 58).

Apesar do avanço com o Decreto de 1934, Ataide Júnior (2018, p. 52) considera o nascimento do Direito Animal no Brasil datado da promulgação da atual Constituição da República Federativa do Brasil, de 1988. A Carta Magna (BRASIL, 1988) instituiu em seu artigo 225, $\S 1^{\circ}$, VII o dever do Poder Público de combater a crueldade contra os animais.

Oportuno o destaque da distinção feita, dentro do próprio artigo 225, § 1ำ VII, no sentido de que a proteção da fauna e da flora não se confunde com a vedação a 
práticas cruéis contra os animais. Na primeira hipótese, valorizam-se as espécies por sua função ecológica, enquanto no segundo caso o que se pretende é a proteção da integridade do animal (ATAIDE JÚNIOR, 2018, p. 52). Sobre essa distinção, também comenta o autor:

Disso deriva a separação, ainda que não absoluta, entre Direito Animal e Direito Ambiental. No Direito Animal Constitucional, o animal nãohumano é indivíduo; no Direito Ambiental Constitucional, o animal nãohumano é componente da fauna e da biodiversidade, elemento da Natureza, com relevância para a manutenção do meio ambiente ecologicamente equilibrado.

Pode-se objetar que a regra da proibição da crueldade contra animais está inserida no capítulo constitucional do meio ambiente, de maneira que sua interpretação deverá ser feita em consonância com os demais componentes do art. 225, que disciplinam o direito fundamental ao equilíbrio ecológico, bem de uso comum do povo. Nessa linha de pensamento, o Direito Animal restaria absorvido pelo Direito Ambiental ou, mais radicalmente, não existiria na Constituição. Essa interpretação, que leva mais em conta a topografia normativa, não se sustenta a partir de um mínimo rigor hermenêutico.

Como sustenta o autor Celso Antonio Pacheco Fiorillo (2017, p. 169), não se pode compreender o Direito Animal como compreendido pelo Direito Ambiental, pois a vedação à crueldade deve ser compreendida no âmbito da dignidade do animal, em seu caráter individual, dado o reconhecimento de que esses sentem dor, experimentam sofrimento e distintas emoções.

Por outro lado, a esfera do Direito Ambiental apresenta preocupações e premissas distintas, a exemplo da sustentabilidade, da manutenção dos recursos naturais e preservação da fauna e da flora (ATAIDE JUNIOR, 2018, p. 53). Tem-se, a exemplo, o reconhecimento de que a criação de gado contribui para a devastação da Floresta Amazônica, conjuntamente com a pecuária (RIVERO; ALMEIDA, 2009). Sobre esse ponto, assim conclui Ataide Júnior (2018, p. 54):

Para o Direito Animal, cada animal não-humano interessa, independentemente da sua função ou influência ecológica, esteja isolado ou em grupo, seja silvestre, seja doméstico ou domesticado, por causa da sua individualidade peculiar de ser vivo que sofre e que, por isso mesmo, merece respeito e consideração. $O$ fato de um ser humano maltratar, ferir, abusar ou mutilar um animal não-humano pouco importa para a manutenção do meio ambiente ecologicamente equilibrado.Esse 
fato viola a dignidade individual do animal submetido à crueldade e não a sua função ecológica.

Para os autores Ingo Wolfgang Sarlet e Tiago Fensterseifer (2017, p. 83), todo o artigo 225 da Constituição da República Federativa do Brasil de 1988 é constituído de diversas cláusulas pétreas. Ataide Júnior, em detida análise apenas do direito dos animais, assenta ser a existência digna um direito individual, atribuível a cada animal, caracterizando-se, portanto, como cláusula constitucional pétrea (2018, p. 54). Como cláusula pétrea, não deve ser admitida qualquer hipótese de retrocesso, ou mesmo de deliberação de eventual proposta para abolir tal direito. Eis o teor do artigo $60, \S 4^{\circ} \mathrm{da}$ Constituição da República Federativa do Brasil de 1988:

Art. 60. A Constituição poderá ser emendada mediante proposta:

(...)

$\S 4$ ํ№̃o será objeto de deliberação a proposta de emenda tendente a abolir:

I - a forma federativa de Estado;

II - o voto direto, secreto, universal e periódico;

III - a separação dos Poderes

IV - os direitos e garantias individuais. (BRASIL, 1988, CRFB, art. 60)

Inspirado no disposto na Constituição da República Federativa do Brasil, a Lei de Crimes Ambientais (9.605/1998) trouxe a previsão em seu artigo 32 o crime de maustratos contra os animais. ${ }^{5}$ Reforçar-se o caráter de regra de Direito Animal - e não Direito Ambiental - à medida em que se tipifica condutas humanas que violam a integridade e a dignidade dos animais não-humanos. Ataide Júnior (2018, p. 56), sobre o tema, assim leciona:

O art. 32 da Lei 9.605/1998, como norma jurídica de Direito Animal, orienta não apenas a tutela penal dos animais, como também a tutela individual ou coletiva dos animais, porquanto estabelece os parâmetros normativos da regra constitucional da proibição da crueldade. Em outras palavras, além da repressão penal das condutas proibidas, será possível usar as normas jurídicas contidas no tipo penal para a defesa individual

5Lei de Crimes Ambientais

Art. 32. Praticar ato de abuso, maus-tratos, ferir ou mutilar animais silvestres, domésticos ou domesticados, nativos ou exóticos. Pena - detenção, de três meses a um ano, e multa.

$\S 1^{\circ}$ Incorre nas mesmas penas quem realiza experiência dolorosa ou cruel em animal vivo, ainda que para fins didáticos ou científicos, quando existirem recursos alternativos.

$\S 2$ ํㅡ pena é aumentada de um sexto a um terço, se ocorre morte do animal. 
ou coletiva dos animais, através de ações individuais (pelo procedimento comum ou por procedimentos especiais) ou coletivas (pela ação civil pública, disciplinada pela Lei $7.347 / 1985$ ou pelas ações coletivas regradas no Título III da Lei 8.078/1990), com caráter inibitório (art. 497, parágrafo único, CPC), preventivo ou repressivo. Toda ação humana que caracterize prática cruel, segundo o art. 32 da Lei 9.605/1998 (ou mesmo segundo o art. $3^{\circ}$ do Decreto 24.645/1934), viola o direito fundamental animal à existência digna e deve ser objeto de ações cíveis inibitórias, preventivas ou repressivas manejadas pelo Ministério Público, pelos substitutos legais do animal vitimado ou pelas associações de defesa animal. Trata-se de uma regra universal de tutela da dignidade animal, pois protege a universalidade dos animais contra a crueldade, independentemente da qualificação do animal como silvestre, doméstico ou domesticado, nativo ou exótico.

Da mesma forma como o consumo de quelônios na Região Amazônica constitui uma violação ao direito ao Meio Ambiente ecologicamente equilibrado, tem-se que as práticas envolvidas no abate e preparo esses animais também expressam crueldade contra os animais. E por essa razão devem ser rechaçadas, à medida em que o Brasil possui um longo histórico de defesa contra a crueldade e os maus-tratos, o que foi, inclusive, constitucionalizado.

\section{CONSIDERAÇÕES FINAIS}

Como restou demonstrado, o consumo de quelônios acompanha a própria história da Região Amazônica. Trata-se de prática documentada desde o período colonial, com provas suficientes para se inferir um grande consumo ao longo dos séculos, tanto das diversas espécies quanto de seus ovos, consideradas iguarias altamente apreciadas pela população local.

Por essa razão, age-se com certa negligência, à medida em que se entende - e até se defende - que o consumo é uma forma de manifestação cultural, intrinsicamente ligada com os valores e hábitos que essas comunidades locais entendem como seus. E toda essa pressão leva ao risco de extinção, documentado há pelo menos quatro décadas.

Há, portanto, manifesta incompatibilidade entre o consumo de tartaruga e seus ovos e o direito ambiental, à medida em que se ameaça a fauna e a biodiversidade, com risco de irreversibilidade (extinção de espécies). Atenta-se, portanto, contra os 
fundamentos da Constituição da República Federativa do Brasil, mais especificamente em seu artigo 225.

Além disso, as práticas envolvidas no consumo de quelônios também se mostram demasiadamente cruéis com os animais, expondo-os a dor e sofrimento. Trata-se, novamente, de violação à Carta Magna, à medida em que essa consolida um direito autônomo dos animais, de não sofreram maus-tratos ou serem expostos à crueldade, o que se viabiliza por uma longa e histórica construção de se vedar práticas lesivas ao bem-estar das espécies não-humanas.

Por todas essas razões, deve-se afastar o consumo de quelônios na Região Amazônica como uma manifestação estritamente cultural, pois se trata de ato lesivo a direitos fundamentais, constituindo, inclusive, um crime, de modo que não pode o Poder Judiciário, os órgãos de controle e a sociedade civil agirem de forma leniente diante de tal prática.

\section{REFERÊNCIAS}

ATAIDE JUNIOR, Vicente de Paula. Introdução ao direito animal brasileiro. Revista Brasileira de Direito Animal. Bahia: Universidade Federal da Bahia, v. 13, n. 3, p. 48-76 set/dez 2018

BENJAMIN, Antonio Herman de Vasconcelos E. O Meio Ambiente na Constituição Federal de 1988. Brasília: Informativo Jurídico da Bibloteca Oscar Saraiva, v. 19, oㅜ 1, p. 37-80, jan/jun, 2008.

BORGES, Luís Antônio Coimbra; REZENDE, José Luiz Pereira; PEREIRA, José Aldo Alves. Evolução da Legislação Ambiental no Brasil. Maringá: Revista em Agronegócio e Meio Ambiente, v.2, no 3, p. 447-466, set/dez, 2009.

BRASIL, Constituição (1988). Constituição da República Federativa do Brasil. Distrito Federal: Senado da República

. Decreto 16.590/1924, de 10 de setembro de 1924. Aprova o rgulamento das casas de diversões públicas. Rio de Janeiro, RJ, set 1924. (Já revogado)

. Decreto 24.645/1934, de 10 de julho de 1934. Estabelece medidas de proteção aos animais. Rio de Janeiro, RJ, jul 1934. (Já revogado)

. Decreto-Lei no 3.688/1941, de 03 de outubro de 1941. Lei das contravenções penais. Rio de Janeiro, RJ, out 1941. 
. Lei 9.605/1998, de 12 de fevereiro de 1998. Dispõe sobre as sanções penais e administrativas derivadas de condutas e atividades lesivas ao meio ambiente, e dá outras providências. Brasília, DF, fev 1998.

COMPARATO, Fábio Konder. O papel do juiz na efetivação dos direitos humanos. In Associação Juízes para a Democracia. São Paulo: Visões Contemporâneas, 2001.

DERANI, Cristiane. Meio ambiente ecologicamente equilibrado: direito fundamental e princípio da atividade econômica. In: Guilherme José Purvin de Figueiredo (org.). Temas de Direito Ambiental e Urbanístico. São Paulo: Max Limonad, 1998.

DIEGUES, Antonio Carlos; ARRUDA, Rinaldo Sergio Vieira. Saberes tradicionais e biodiversidade no Brasil. Brasília: Ministério do Meio Ambiente, 2001.

FIORILLO, Celso Antonio Pacheco. Curso de direito ambiental brasileiro. São Paulo: Editora Saraiva, 2017

FREITAS, Vladimir Passos de; FREITAS, Gilberto Passos de. Crimes contra a natureza. São Paulo: Revista dos Tribunais, 2005.

GARCIA, Leonardo; THOMÉ, Romeu. Direito Ambiental. Princípios, competências constitucionais. $8^{\mathrm{a}}$ ed. Salvador: Juspodivm, 2015.

JESUS, Damásio E. de. Direito penal: parte geral. 28ª ed. São Paulo: Editora Saraiva, 2005.

LEVAL, Laerte Fernando. Direito dos animais: o direito deles e o nosso direito sobre eles. $2^{\underline{a}}$ ed. São Paulo: Editora Mantiqueira, 2004.

MARROTA, Clarice Gomes. Princípio da dignidade dos animais: reconhecimento jurídico e aplicação. Coleção Direitos fundamentais e acesso à justiça no estado constitucional de direito em crise. Coordenação: gregório Assagra de Almeida. Belo Horizonte: Editora D’Plácido, 2019.

MOREIRA, Paula Kamila Fonseca Neto; SILVA, Wilian Vaz; BALESTRA, Rafael Antônio Machado. A conservação da tartaruga da Amazônia em unidades de conservação no Médio Rio Araguaia. Brasília: ICMBIO, 2016.

REBÊLO, George; PEZZUTI, Juarez. Percepções sobre o consumo de quelônios na Amazônia: sustentabilidade e alternativas ao modelo atual. Revista Ambiente \& Sociedade, ano III, $\mathrm{n}^{\circ}$ 6, $1^{\circ}$ sem/2은 $\mathrm{sem}, 2000$. 
SILVA, José Afonso da..Curso de Direito Constitucional Positivo. 23ª ed. São Paulo: Malheiros Editores, 2004.

TAKADA, Mariana; RUSCHEL, Carolina Vieira. Eficácia das penas nos crimes ambientais. Itajaí: Revista Eletrônica do Centro de Ciências Sociais e Jurídicas da UNIVALI, v. 3, no 3, p. 1043-1062, 3ํㅡㄹ trimestre de 2012. 